\title{
Role of expansion joint in the study of seismic analysis of a multi-storied building
}

\author{
Meera Arun $^{1}$, T Srinivas $^{2}$, PVVSSR Krishna ${ }^{3}$ \\ ${ }^{1} \mathrm{M}$ Tech Scholar, GRIET Hyderabad, India \\ ${ }^{2}$ Professor, GRIET Hyderabad, India \\ ${ }^{3}$ Assistant Professor, GRIET Hyderabad, India
}

\begin{abstract}
In this paper, the study on the multi-storied building with and without expansion joint when it is subjected to seismic forces in both $\mathrm{x}$ and $\mathrm{y}$ direction are taken into consideration. By maintain same floor area of different plans the expansion joint is provided along the weaker column forces stretch and stiffed the building in order to make more resistant when compared to the plans without expansion joints. The analysis is done using ETABS 2016. The parameters such as shear force and bending moment at the critical column are considered and compared for with expansion joint and without expansion joint. It is concluded that the L shaped building shear force is being decreased from the bottom to top storey of the building when compared to without expansion joint. The effect of expansion joint is shown effectively on U-shaped building in terms of reduction of shear force and bending moment when compared to L-shaped and Tshaped, it is because of providing two expansion joints since there are two critical and weaker columns stretch. When it comes to economy of the structure, the cost of the construction of the structure with expansion joint is relatively high but it can resistant far better in case of seismic forces. The future scope of the study can be the type of filler material to be used such that the reduction of cost and to maintain structure integrity.
\end{abstract}

\section{Introduction}

The study of a symmetric plan building was considered to be superior than that of the asymmetric plan building when the floor area is kept constant. To overcome the effect of symmetricity problems in the asymmetric plans the idea of providing the expansion joint has taken into consideration. The weaker columns in the asymmetric shaped building are identified initially after the seismic analysis of a 8 storied building. The floor area is constant in both the asymmetric and symmetric shaped building. The seismic analysis results, tables, and graphs are taken into consideration for the study of the effect of seismic analysis on the multi-storied building using E-Tabs 2016. Through thorough study of the results the weaker columns are identified. Generally ${ }^{1}$ the deflection of the structure will be $2 \%$. The stretch of weaker columns are to be made strong by providing expansion joint in that region. In this study the height of the building is considered as $21 \mathrm{~m}$, so the expansion joint provided is $0.5 \mathrm{~m}$ at the weaker sections through out the height and width of the structure. These expansion joints make the seismic forces effect to be minimised.

The expansion joints are provided within the structure as isolation joints and to permit the separate segments in the structural frame, the provision also interacts with the thermal expansion and contraction with respect to the climatic and temperature variations without effecting the building serviceability and integrity of the structure [anil kumar]. The expansion filler materials can be different such as aluminium, stainless steel, brass, PVC and copper. Expansion joints can be used in any type of multi-storied structure such as residential, commercial and industrial buildings.

Generally the expansion joints are provided in the roads, runways, bridges, warehouses, hangers and high rise buildings. This paper is the study of Role of expansion joint when the structure is subjected to seismic forces in the $\mathrm{X}$ and $\mathrm{Y}$ direction. It can also be compared with and without expansion joint of the asymmetric shaped building i.e, L shaped, T- shaped and U- shaped structures

\section{Need of providing expansion joint}

Generally the expansion joints are provided in the roads, runways, building joints, cutting slabs of the reinforced concrete when the sections are too long, these expansion joints are provided in order to thermal conditions when it is subjected to contraction and expansion during cold weather and hot weather conditions respectively. It is considered as a little space for moving in and out. As per the earthquake tips, in this study the expansion joints is considered to stiffer the weaker column and to restrict the seismic forces. RCC framed building is differed from steel framed design due to its

*Corresponding Author: srinu.tummala@gmail.com 
movement during seismic forces. There is no provision of expansion joints in the small buildings because, the smaller buildings are subjected to very low expansion. If the expansion joint is not provided then the structure will be subjected to the internal compressive forces, these leads to compressive stresses and these stresses reach to the highest value and leads to the failure of the structure. These expansion joints are provided when

1. There is change in the material.

2. The structure is a high rised or multi-storied building

3. For different building shaped i.e structural asymmetric buildings

These expansion joints are to be provide from the base of the building to the top of the structure. The amount of expansion joint in this study is taken as $2 \%$ of the height of the building.

\subsection{Advantages of Providing the Expansion Joint in the Structure}

(I) It provides structural stability and maintain structural integrity when subjected to seismic forces.

(II) It can tackle the forces of expansion and contraction when thermal stress comes into frame.

\subsection{Disadvantages of providing the expansion joint in the structure}

(I) Structure have the chances of attacking due to pest.

(II) Chances of getting leakage due to water.

(III) Poor workmanship can lead to structural damage.

\section{Plan configurations in this paper}

In this project, 3 different plan configurations with and without expansion joint with same floor area ratio are considered. The different 3 plans are as shown in 1,2,3,4,5 and 6

(1) L- Shaped building with expansion joint

(2) L-Shaped building without expansion joint

(3) T-Shaped building with expansion joint

(4) T-Shaped building without expansion joint

(5) U- Shaped building with expansion joint

(6) U-Shaped building without expansion joint

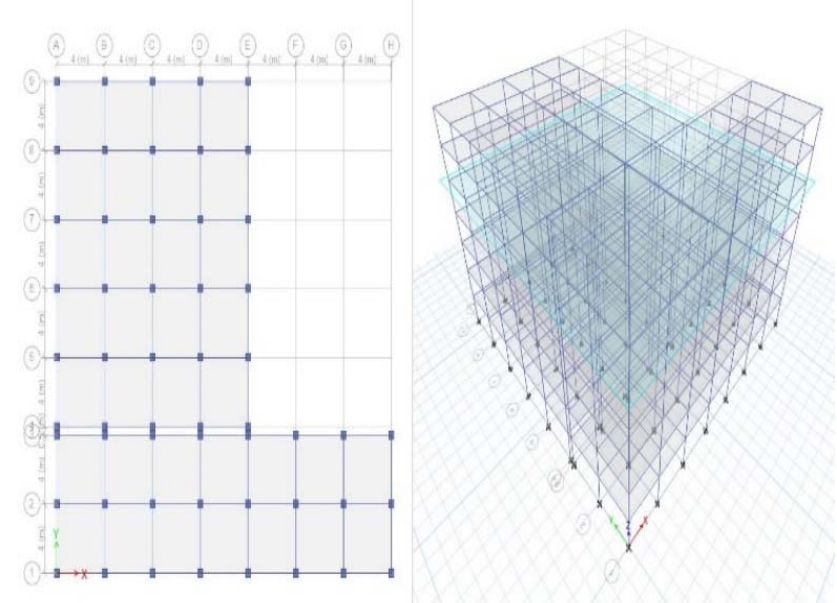

Fig.1. L-Shaped Plan and elevation with expansion joint of 8 storied building
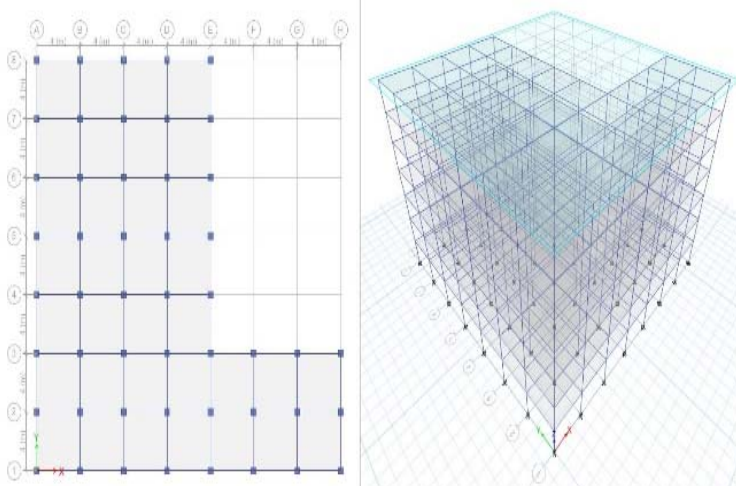

Fig 2. L-Shaped Plan and elevation without expansion joint of 8 storied building

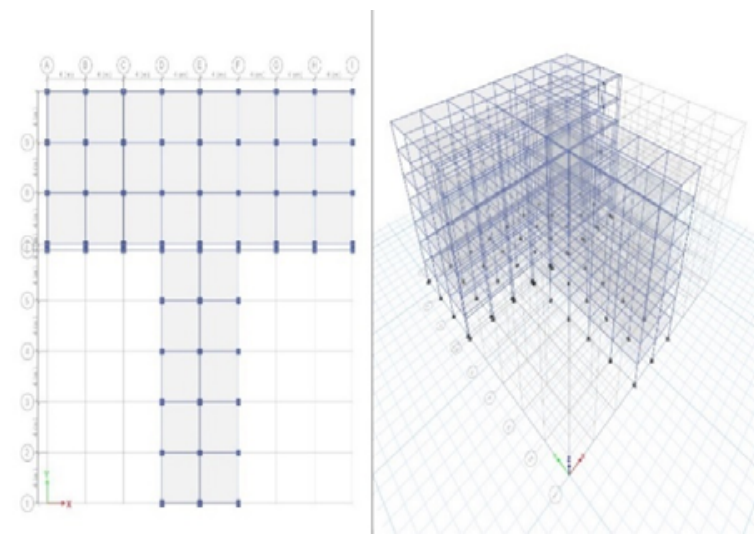

Fig.3. T-Shaped Plan and elevation with expansion joint of 8 storied building 


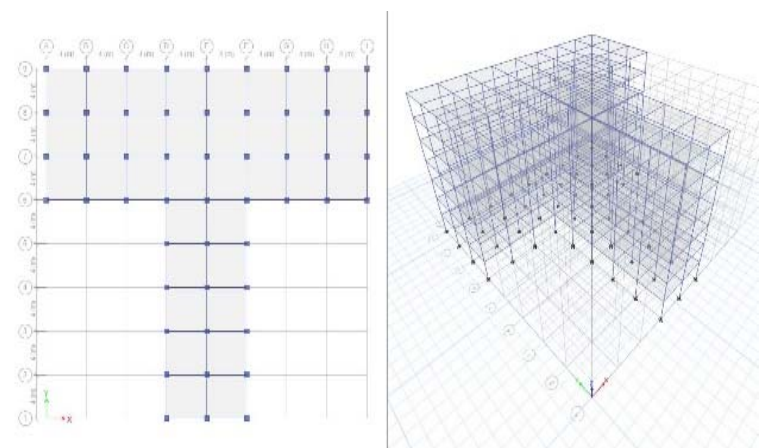

Fig.4. T-Shaped Plan and elevation without expansion joint of 8 storied building
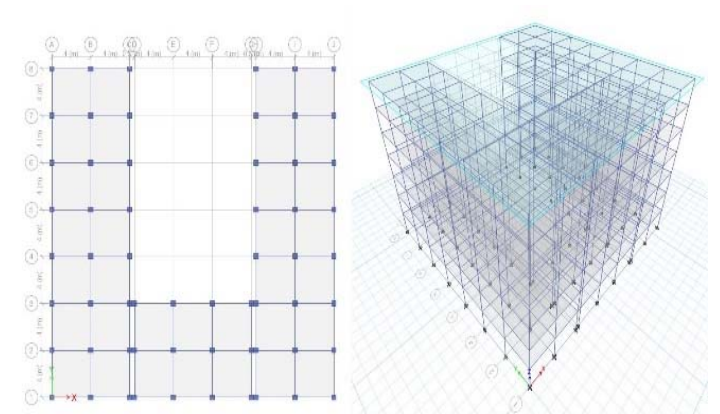

Fig.5. U-Shaped Plan and elevation with expansion joint of 8 storied building
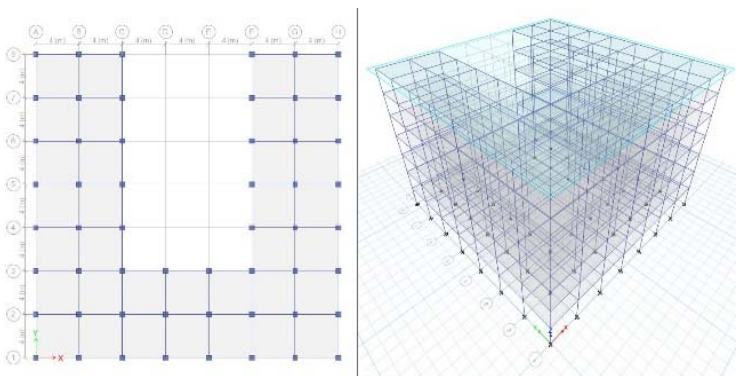

Fig.6. U-Shaped Plan and elevation with expansion joint of 8 storied building

\section{Description about building and the material specifications in this study}

A 8 storied ordinary moment resisting frame of different plan configurations with the same floor are is considered and studied by providing expansion joint of $0.5 \mathrm{~m}$ along the weaker columns, with fixed end conditions.

The column size is $450 \mathrm{~mm} \mathrm{X} 450 \mathrm{~mm}$, the beam size is $300 \mathrm{~mm} \times 350 \mathrm{~mm}$, The thickness of the slab is 150 $\mathrm{mm}$ and the material properties are M30 and $\mathrm{Fe}-415$. The density of the brick is $20 \mathrm{KN} / \mathrm{m} 3$. The seismic zone $\mathrm{V}$ is considered, the importance factor being 1 and response reduction factor being 5 , and the time period is taken as $0.735 \mathrm{sec}$ from the calculations.
The critical section of the building is selected, as the critical section will be at the edges or the corners of the building. The building plan is made into two blocks and the expansion joint with the increased number of columns is considered. Even the economy of the building may be effected but the safety of the building comes first when compared to its economy. The Shear force and Bending moment of the critical sections are considered for both with and without expansion joints for all the three different plan configurations.

\section{Results}

The shear force and Bending moment for the building with expansion joint and without expansion joint are compared for all the three models and the results are tabulated below for $\mathrm{X}$ and $\mathrm{Y}$ directions. The below tables are tabulated from the Etabs software and computed in the results and conclusions. The effect of both Shear force and Bending Moment are shown clearly.

Table 1. Shear Force and Bending moment for L-Shaped building with and without Expansion joint in Ex direction

\begin{tabular}{|c|c|c|c|c|}
\hline \multicolumn{5}{|c|}{ L Shaped X-Direction } \\
\hline \multirow{2}{*}{ Storey } & \multicolumn{2}{|c|}{ Shear Force (kN) } & \multicolumn{2}{c|}{$\begin{array}{c}\text { Bending Moment } \\
\text { (kN-m) }\end{array}$} \\
\cline { 2 - 5 } & Normal & Expansion & Normal & Expansion \\
\hline 7 & 16.4 & 5.0784 & -34.1821 & -20.1224 \\
\hline 6 & 37.0432 & 20.1403 & -60.1426 & -41.5748 \\
\hline 5 & 52.6636 & 28.5963 & -73.9822 & -46.6603 \\
\hline 3 & 62.5465 & 34.0526 & 85.9214 & -47.3111 \\
\hline 2 & 67.8771 & 37.4084 & 100.5904 & 54.8771 \\
\hline \multirow{2}{*}{3} & 65.7987 & 39.9175 & 116.7625 & 72.1686 \\
\hline
\end{tabular}


Table 2. Shear Force and Bending moment for L-Shaped building with and without Expansion joint in Ey direction

\begin{tabular}{|c|c|c|c|c|}
\hline \multicolumn{5}{|c|}{ L Shaped Y-Direction } \\
\hline \multirow{2}{*}{ Storey } & \multicolumn{2}{|c|}{ Shear Force (kN) } & \multicolumn{2}{|c|}{$\begin{array}{c}\text { Bending Moment(kN- } \\
\mathrm{m})\end{array}$} \\
\hline & Normal & Expansion & Normal & Expansion \\
\hline 7 & -1.44 & -0.23 & -1.97 & -0.31 \\
\hline 6 & -0.64 & -0.00 & -1.15 & -0.17 \\
\hline 5 & -0.64 & 0.04 & -0.98 & -0.17 \\
\hline 4 & -0.43 & 0.11 & -0.61 & -0.20 \\
\hline 3 & -0.26 & 0.18 & 0.46 & 0.34 \\
\hline 2 & -0.20 & 0.14 & 0.44 & 0.38 \\
\hline 1 & 0.29 & 0.36 & 0.90 & 1.09 \\
\hline
\end{tabular}

Table 3. Shear Force and Bending moment for T-Shaped building with and without Expansion joint in Ex direction

\begin{tabular}{|c|c|c|c|c|}
\hline \multicolumn{5}{|c|}{ T Shaped X-Direction } \\
\hline \multirow{2}{*}{ Storey } & \multicolumn{2}{|c|}{ Shear Force $(k N)$} & \multicolumn{2}{|c|}{$\begin{array}{c}\text { Bending } \\
\text { Moment(kN-m) }\end{array}$} \\
\hline & Normal & Expansion & Normal & Expansion \\
\hline 7 & 16.88 & 14.80 & -35.01 & -30.80 \\
\hline 6 & 37.76 & 33.29 & -61.21 & -53.98 \\
\hline 5 & 53.61 & 47.31 & -75.26 & -66.47 \\
\hline 4 & 63.63 & 56.32 & 87.50 & 77.41 \\
\hline 3 & 68.94 & 61.10 & 102.33 & 90.60 \\
\hline 2 & 70.33 & 62.42 & 118.37 & 104.85 \\
\hline 1 & 66.18 & 59.13 & 157.42 & 140.18 \\
\hline
\end{tabular}

Table 4. Shear Force and Bending moment for T-Shaped building with and without Expansion joint in Ey direction

\begin{tabular}{|c|c|c|c|c|}
\hline \multicolumn{5}{|c|}{ T Shaped Y-Direction } \\
\hline \multirow{2}{*}{ Storey } & \multicolumn{2}{|c|}{ Shear Force (kN) } & \multicolumn{2}{c|}{$\begin{array}{r}\text { Bending Moment (kN- } \\
\text { m) }\end{array}$} \\
\cline { 2 - 5 } & Normal & Expansion & Normal & Expansion \\
\hline 7 & -1.6933 & -0.981 & 2.2975 & -1.3193 \\
\hline 6 & -1.0796 & -0.4313 & -1.6809 & -0.7197 \\
\hline 5 & -1.139 & -0.7003 & -1.6676 & -1.028 \\
\hline 4 & -0.9986 & -0.4287 & -1.4559 & -1.4559 \\
\hline 3 & -0.8107 & -0.3453 & -1.144 & -0.4874 \\
\hline 2 & -0.5879 & -0.2166 & -0.8214 & -0.3268 \\
\hline 1 & -0.1046 & 0.0562 & 0.2301 & 0.1417 \\
\hline
\end{tabular}

Table 5. Shear Force and Bending moment for U-Shaped building with and without Expansion joint in Ex direction

\begin{tabular}{|c|c|c|c|c|}
\hline \multicolumn{5}{|c|}{ U Shaped X-Direction } \\
\hline \multirow{2}{*}{ Storey } & \multicolumn{2}{|c|}{ Shear Force $(k N)$} & \multicolumn{2}{|c|}{$\begin{array}{c}\text { Bending Moment (kN- } \\
\text { m) }\end{array}$} \\
\hline & Normal & Expansion & Normal & Expansion \\
\hline 7 & 18.11 & 0.19 & -37.02 & -10.71 \\
\hline 6 & 39.23 & 24.83 & -63.42 & -45.09 \\
\hline 5 & 55.73 & 38.87 & -78.16 & -57.18 \\
\hline 4 & 66.11 & 48.58 & 91.05 & 66.40 \\
\hline 3 & 71.53 & 55.75 & 106.40 & 85.38 \\
\hline 2 & 72.66 & 63.19 & 122.75 & 111.53 \\
\hline 1 & 67.14 & 62.31 & 160.45 & 146.47 \\
\hline
\end{tabular}


Table 6. Shear Force and Bending moment for U-Shaped building with and without Expansion joint in Ey direction

\begin{tabular}{|c|c|c|c|c|}
\hline \multicolumn{4}{|c|}{ U Shaped Y-Direction } \\
\hline \multirow{2}{*}{ Storey } & \multicolumn{2}{|c|}{ Shear Force (kN) } & \multicolumn{2}{c|}{$\begin{array}{c}\text { Bending Moment } \\
(\mathbf{k N}-\mathbf{m})\end{array}$} \\
\cline { 2 - 5 } & Normal & Expansion & Normal & Expansion \\
\hline 7 & -1.61 & -1.88 & 2.19 & -2.59 \\
\hline 6 & -1.04 & -1.60 & -1.62 & -2.5 \\
\hline 5 & -1.10 & -1.90 & -1.61 & -2.89 \\
\hline 4 & -0.96 & -2.01 & -1.41 & -3.01 \\
\hline 3 & -0.78 & -1.92 & -1.10 & -2.82 \\
\hline 2 & -0.54 & -1.55 & -0.82 & -2.20 \\
\hline 1 & -0.08 & -0.52 & 0.20 & 0.20 \\
\hline
\end{tabular}

\section{Conclusions}

1. With the introduction of expansion joint, a considerable decrease in the shear force was found for L-Shaped building from bottom storey to top storey when compared with the same building without any expansion joint.

2. For T-Shaped building, the magnitude of shear force has decreased to a very little extent in both $\mathrm{X}$ and $\mathrm{Y}$ directions when compared with the same building without any expansion joint.

3. For U-Shaped building, the magnitude of shear force has drastically reduced in X direction when compared with the same building without any expansion joint.

4. The effect of expansion joint is shown effectively on U-Shaped building in terms of reduction in shear force values than L-shaped and T-Shaped building.

5. The magnitude of Bending moment has been decreased from lower storey to higher storeys in all the buildings from a positive moment to negative moment with the introduction of expansion joint.

6. The effect of expansion joint is shown effectively on U-Shaped building in terms of reduction in bending moment values than $\mathrm{L}$-shaped and $\mathrm{T}$ Shaped building.

\section{References}

1. Rathod, P., \& Chandrashekar, R. (2017). (IRJET) Volume, 4, 1101-1108 (2017)

2. Guleria, A.. IJERT, 3(5). (2014)

3. Shanker, B. J. U., Kumar, G. K., \& Kiran, R. S. (2021, July).. In AIP Conf. Proc. (Vol. 2358, No. 1, p. 050003). AIP Publishing LLC. (2021)

4. Patil, M. N., \& Sonawane, Y. N. IJEIT 4(9). (2015)
5. Lavanya, C. V. S., Pailey, E. P., Sabreen, M. M., \& Sekhar, U. P. B. C. J. Civil Eng. Tech., 8(4), 1845-1850 (2017)

6. Manchalwar, A., \& Bakre, S. V. Soil Mechanics and Foundation Engineering, 57(2), 170-177. (2020)

7. T.Srinivas and M. Abinay Raj, Int. J. of Eng.and Adv. Tech. (IJEAT), ISSN: 2249 - 8958, Volume-8 Issue-6 (2019)

8. T.srinivas and P. Manoj Anand, Int. J. of Innov. Tech. and Explor. Eng.g (IJITEE), ISSN: 22783075, Volume-8 Issue-12 (2019)

9. T.Srinivas and G. Sukesh Reddy, Int. J. of Eng.and Adv. Tech. (IJEAT), ISSN: $2249-$ 8958, Volume-9 Issue-1 (2019)

10. T.Srinivas and R. N. Koushik, Int. J. of Innov. Tech. and Explor. Eng.g (IJITEE), ISSN: 22783075, Volume-8 Issue-12 (2019), PP 112-117.

11. K. Sai Gopi, Dr. T. Srinivas and S. P. Raju V, E3S Web of Conferences ICMED 184, 01084GRIET, 28-29 February, https://doi.org/10.1051/e3sconf/2020184011084 (2020)

12. Jagannadha Kumar, M.V., Jagannadha Rao, K., Dean Kumar, B., Srinivasa Reddy, V., Int. J. of Civil Eng. and Tech., 9(7), pp. 1133-1141 (2018)

13. Ganta, J.K., Seshagiri Rao, M.V., Mousavi, S.S., Srinivasa Reddy, V., Bhojaraju, C., Structures 28, pp. 956-972 (2020)

14. Karthik Rao, R., Bobba, P.B., Suresh Kumar, T., Kosaraju, S. Materials Today: Proceedings, 26, pp. 3085-3089, 2019

15. Naidu, K.S.S.T., Rao, M.V.S., Reddy, V.S., Int. J. of Innov. Tech. and Explor. Eng.g (IJITEE), 8(9 Special Issue 2), pp. 641-642 (2019)

16. Chandana Priya, C., Seshagiri Rao, M.V., Srinivasa Reddy, V., Int. J. of Civil Eng. and Tech., 9(11), pp. 2218-2225 (2018)

17. Satya Sai Trimurty Naidu, K., Seshagiri Rao, M.V., Srinivasa Reddy, V., Int. J. of Civil Eng. and Tech., 9(11), pp. 2383-2393 (2018)

18. Supriya, Y., Srinivasa Reddy, V., Seshagiri Rao, M.V., Shrihari, S., Int. J. of Rec. Tech. and Engi., 8(3), pp. 5381-5385 (2019)

19. M. Vaishnavi and P. B. Bobba, 2019 IEEE 5th International Conference for Convergence in Technology (I2CT), 2019, pp. 1-6

20. Kotkunde, N., Krishna, G., Shenoy, S.K., Gupta, A.K., Singh, S.K. International Journal of Material Forming, 10 (2), pp. 255-266 (2017)

21. Govardhan, D., Kumar, A.C.S., Murti, K.G.K., Madhusudhan Reddy, G. Materials and Design, 36, pp. 206-214. (2012)

22. Kumar, P., Singhal, A., Mehta, S., Mittal, A. Journal of Real-Time Image Processing, 11 (1), pp. 93-109. (2016)

23. Raghunadha Reddy, T., Vishnu Vardhan, B., Vijayapal Reddy, P. International Journal of Applied Engineering Research, 11 (5), pp. 30923102 (2016)

24. Hussaini, S.M., Krishna, G., Gupta, A.K., Singh, 
S.K. Journal of Manufacturing Processes, 18, pp. 151-158 (2015)

25. S. U.M. Rao,T.H. Rao, K. Satyanarayana, and B. Nagaraju, Materials Today: Proceedings, 5(2), 4958 (2018)

26. Manchalwar, A., \& Bakre, S. V. International Journal of Dynamics and Control, 1-10. (2020)

27. Manchalwar, A., \& Bakre, S. V. Proceedings of the ICESB 172(11), 836-856(2019)

28. Sravya, G. J., \& Manchalwar, A. In E3S Web of Conf. (Vol. 184, p. 01097). EDP Sci. (2020)

29. Sravya, G. J. S., \& Manchalwar, A. Seismic (IJRTE), 12336-12339 (2020)

30. Nirmala, G., \& Manchalwar, A.. In E3S Web of Conf.(Vol. 184, p. 01078). EDP Sci.(2020)
31. Reddy, N. O., \& Manchalwar, A. In E3S Web of Conf. (Vol. 184, p. 01099). EDP Sciences. (2020)

32. K. satyanarayana, S. K. Singh, T. Buddi, K. Anil and A. Ul Haq, Advances in Materials and Processing Technologies, 6(2), 365 (2020)

33. B. J. Varghese, P. B. Bobba and M. Kavitha, 2016 IEEE 7th Power India International Conference (PIICON), 2016, pp. 1-6

34. Manchalwar, A., \& Bakre, S. V. JVET of7(3), 261-275. (2019).

35. Manchalwar, A., \& Bakre, S. V. JIEI Series A, 97(4), 415-425 (2016). 